\title{
Measurement and Correlation of the Solubility of Sodium 2-Chlorotoluene-4-sulfonate in Selected Pure Solvents and Aqueous Organic Solutions
}

Shi-Liang Liu, Hai-Ming Li, Guang Han, Yuan-Xiao Li, Guo-Liang Zhang, Feng-Bao

Zhang, Qing Xia*

School of Chemical Engineering and Technology, Tianjin University, Tianjin, 300072, PR China.

\footnotetext{
* Corresponding author.
}

Tel.: +86-22-27400292; Fax: +86-22-27408778.

E-mail address: xiaqing@tju.edu.cn. (Qing XIA) 


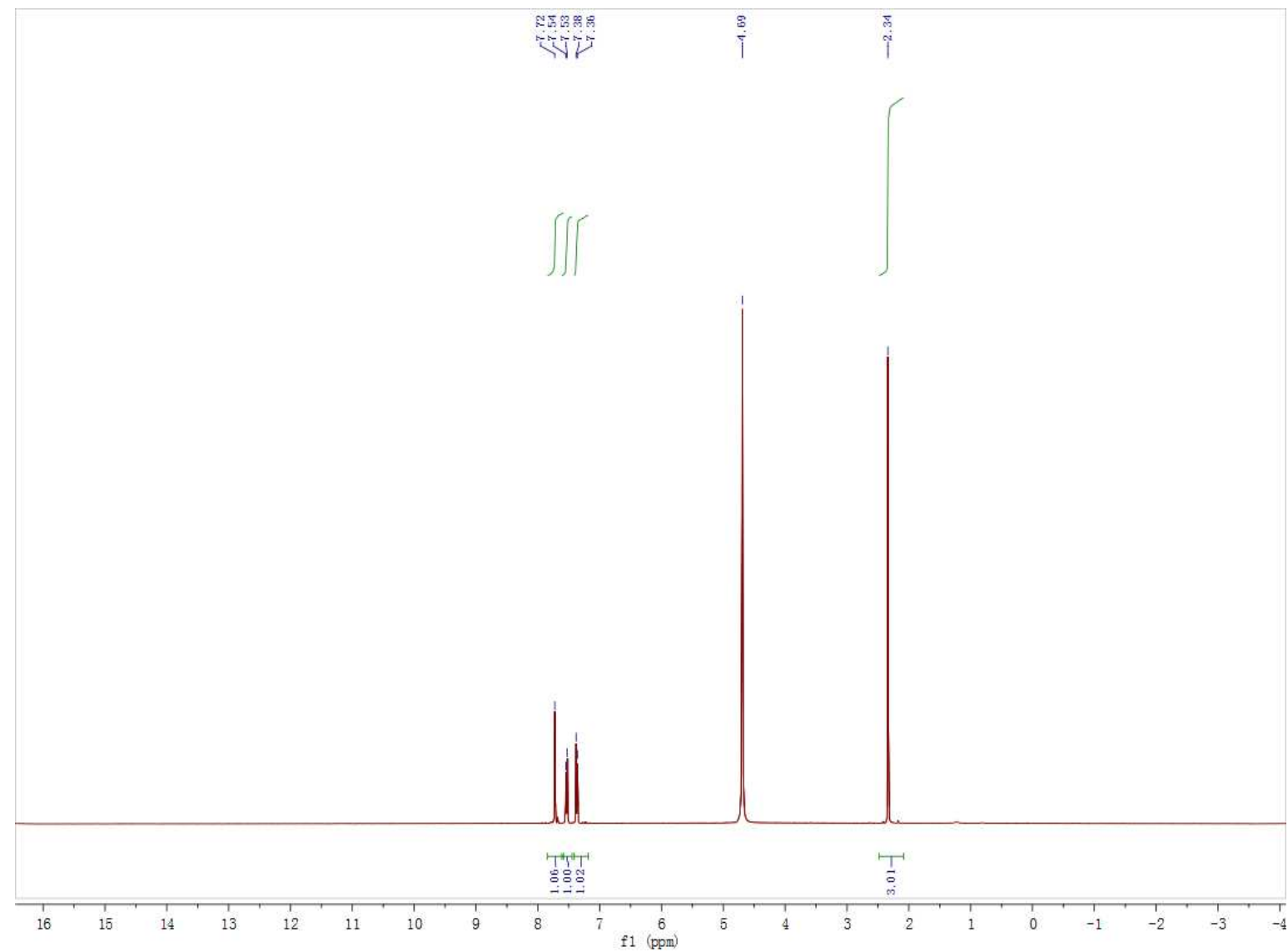

Figure S1. ${ }^{1} \mathrm{H}$ NMR of synthesized CTSNa before dissolution.

The solvent residual peak $\left(\mathrm{H}_{2} 0 \delta=4.69 \mathrm{ppm}\right)$. 


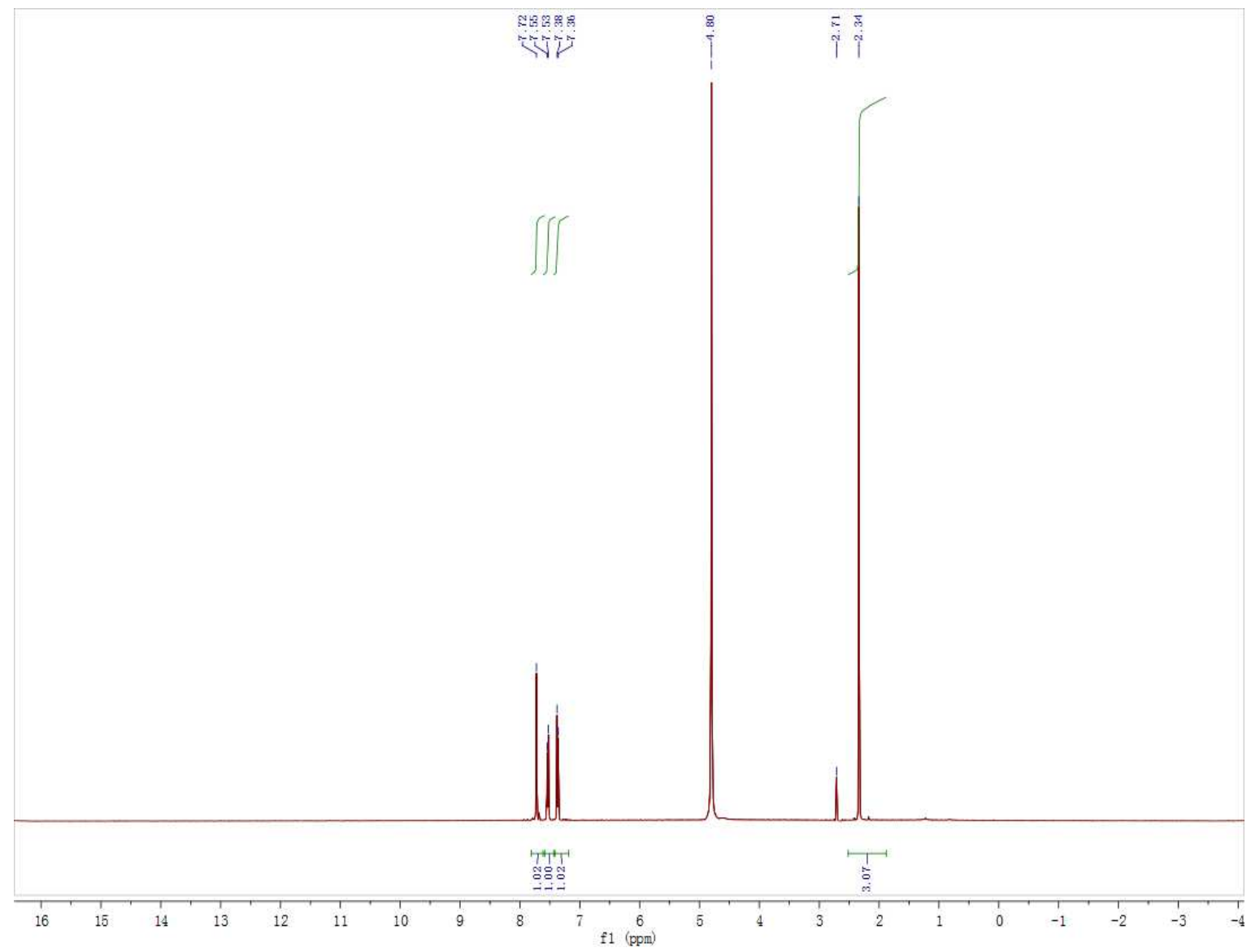

Figure S2. ${ }^{1} \mathrm{HNMR}$ of CTSNa after dissolution ( precipitated from the DMSO).

The solvent residual peak (DMSO $\delta=2.71 \mathrm{ppm} ; \mathrm{H}_{2} 0 \delta=4.80 \mathrm{ppm}$ ). 


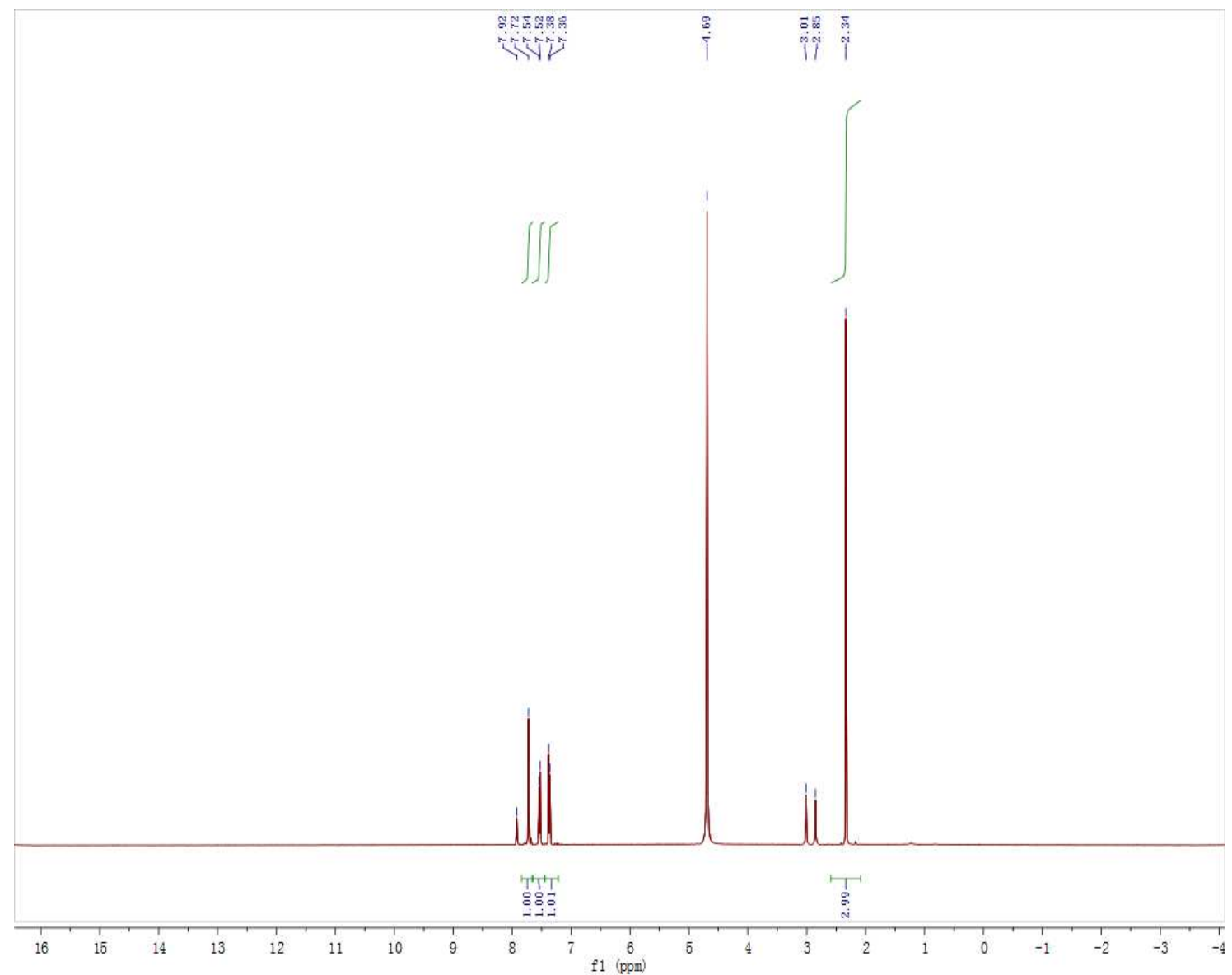

Figure S3. ${ }^{1} \mathrm{HNMR}$ of CTSNa after dissolution ( precipitated from the DMF).

The solvent residual peak $\left(\mathrm{H}_{2} 0 \delta=4.69 \mathrm{ppm}\right.$; DMF $\left.\delta=2.85 \mathrm{ppm}, 3.01 \mathrm{ppm}, 7.92 \mathrm{ppm}\right)$. 